\title{
Upper rectus abdominis paralysis after robot-assisted thoracic oncology surgery with cryoanalgesia: A rare complication
}

Davina Wildemeersch, MD, ${ }^{\mathrm{a}}$ Suresh Krishan Yogeswaran, MD, ${ }^{\mathrm{b}}$ Guido Vyncke, MD,${ }^{\mathrm{c}}$ Ine Meeus, MD, ${ }^{\mathrm{a}}$ Tim Wielandt, MD, ${ }^{\mathrm{c}}$ Guy Hans, MD, PhD, ${ }^{\mathrm{a}}$ and Eric Vanduynhoven, MD, ${ }^{\mathrm{a}}$ Edegem, Belgium

From the Departments of ${ }^{\mathrm{a}}$ Pain Medicine, Multidisciplinary Pain Center, ${ }^{\mathrm{b}}$ Thoracic Surgery, and ${ }^{\mathrm{c}}$ Physical Medicine, Antwerp University Hospital, Edegem, Belgium.

Disclosures: The authors reported no conflicts of interest.

The Journal policy requires editors and reviewers to disclose conflicts of interest and to decline handling or reviewing manuscripts for which they may have a conflict of interest. The editors and reviewers of this article have no conflicts of interest.

Received for publication April 30, 2021; accepted for publication Sept 14, 2021; available ahead of print Sept 20, 2021.

Address for reprints: Davina Wildemeersch, MD, Department of Pain Medicine, Multidisciplinary Pain Center, Antwerp University Hospital, Drie Eikenstraat 655, 2650 Edegem, Belgium (E-mail: Davina. wildemeersch@uza.be).

JTCVS Techniques 2021;10:534-7

2666-2507

Copyright (C) 2021 The Author(s). Published by Elsevier Inc. on behalf of The American Association for Thoracic

Surgery. This is an open access article under the CC BY-NC-ND license (http://creativecommons.org/licenses/bync-nd/4.0/).

https://doi.org/10.1016/j.xjtc.2021.09.028

Intercostal nerve damage resulting in motor dysfunction is more infrequent compared with sensory loss after thoracic surgery. Considering intercostal nerves as mixed-type nerves, chronic pain incidence is up to $50 \%,{ }^{1}$ and there is a strong discrepancy in the presence of paralysis. Only a few case reports of paralysis after video-assisted thoracic surgery (VATS) have been published. We report the first case of rectus abdominis atrophy after robot-assisted VATS (RA-VATS).

\section{CASE REPORT}

A 55-year-old man underwent RA-VATS lobectomy due to malignancy (17 mm carcinoid tumor, pT1 N0 G1 R0 [based on TNM eighth edition]). Preoperative clinical examination showed no abnormalities. To expedite enhanced recovery after surgery, as per institutional protocol, cryoanalgesia (Metrum Cryoflex; Cryo-S, Warsaw, Poland) was performed intraoperatively. The team has acquired solid expertise in the use of cryotherapy for pain treatment ( $>500$ procedures) and has been using this technique during surgery without any complication. Few potential side effects are reported, including local bleeding and bruising; no motor dysfunction has been described. Unsurprisingly, local hypoesthesia may develop. Surgical installation and 4-port placement are illustrated in Figure 1.

The cryoprobe was inserted through the preexisting entry ports and applied under direct visualization at intercostal nerves 6, 7, and 8. Cryoablation was performed lege artis for 90 seconds at a temperature of $-80^{\circ} \mathrm{C}$ followed by a

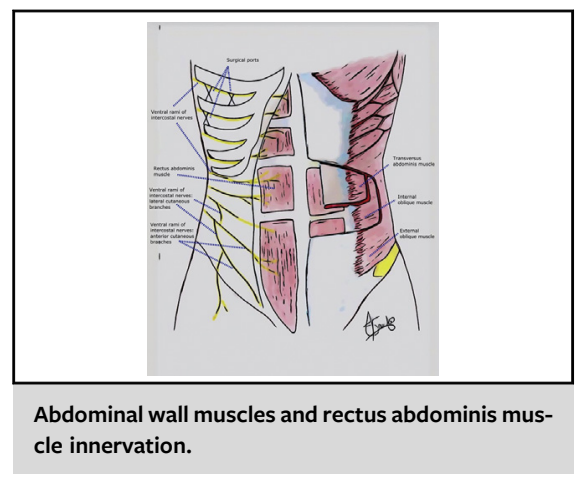

CENTRAL MESSAGE

Permanent rectus paralysis after

lung surgery is rare but with potentially esthetic repercussions. Patients could benefit from early recognition of lesions responsible for postoperative discomfort.

See Commentaries on pages 538 and 540.

defreezing period resulting in a nerve lesion of Seddon and Sunderland classification axonotmesis grade II, which spontaneously resolved after 4 months. ${ }^{2}$

One of the author (S.K.Y.) have made a video tutorial on robot-assisted lung surgery for The Multimedia Manual of Cardio-Thoracic Surgery on behalf of the European Association for Cardio-Thoracic Surgery, available at https:// mmcts.org/tutorial/1481. RA-VATS has increased in popularity during the past 2 decades because it offers 3-dimensional optics, increased instrument and wrist flexibility compared with classical VATS, and for patients it offers improved quality of life and shorter hospital stays compared with open surgery. In this video tutorial, we demonstrate a RA-VATS lobectomy in a patient with a tumor in the right middle lobe. The patient presented in the case report had identical tumor characteristics and mass localization. 

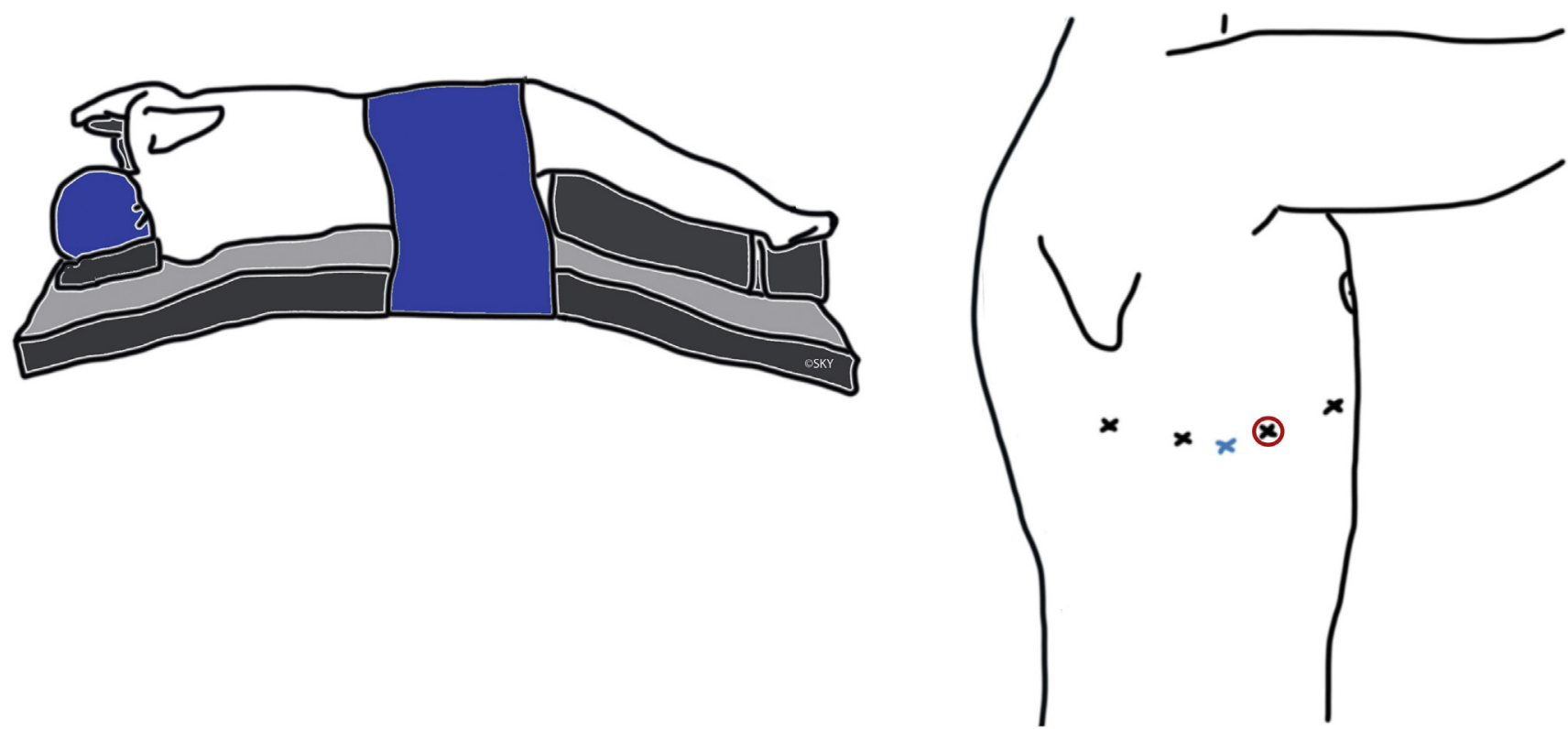

FIGURE 1. Patient installation and port placement. For the robot-assisted thoracoscopic surgery, 4 ports are used. These were placed in the sixth intercostal space, over the top of the seventh rib. There is 1 assisting port (blue cross), this is placed 1 intercostal space below the other ports, just over the top of the eighth rib. The camera port is marked with a red circle. Port characteristics: $8 \mathrm{~mm}$ infrascapular port, $12 \mathrm{~mm}$ port, assisting port (blue cross), $8 \mathrm{~mm}$ camera port, $12 \mathrm{~mm}$ port.

A localized painful area below the levels of the cryoanalgesic procedure with numeric rating score of 3 was declared during coughing. No hyperalgesia or allodynia was reported besides the expected hypoesthesia at dermatomes Th6, Th7, and Th8. The patient returned 4 months later with painless right-sided abdominal swelling (Figure 2, $A$ ) that he noticed several weeks after surgery.

A computed tomography scan ruled out underlying pathology. In addition to the suggestive clinical examination, electromyography evaluation confirmed permanent

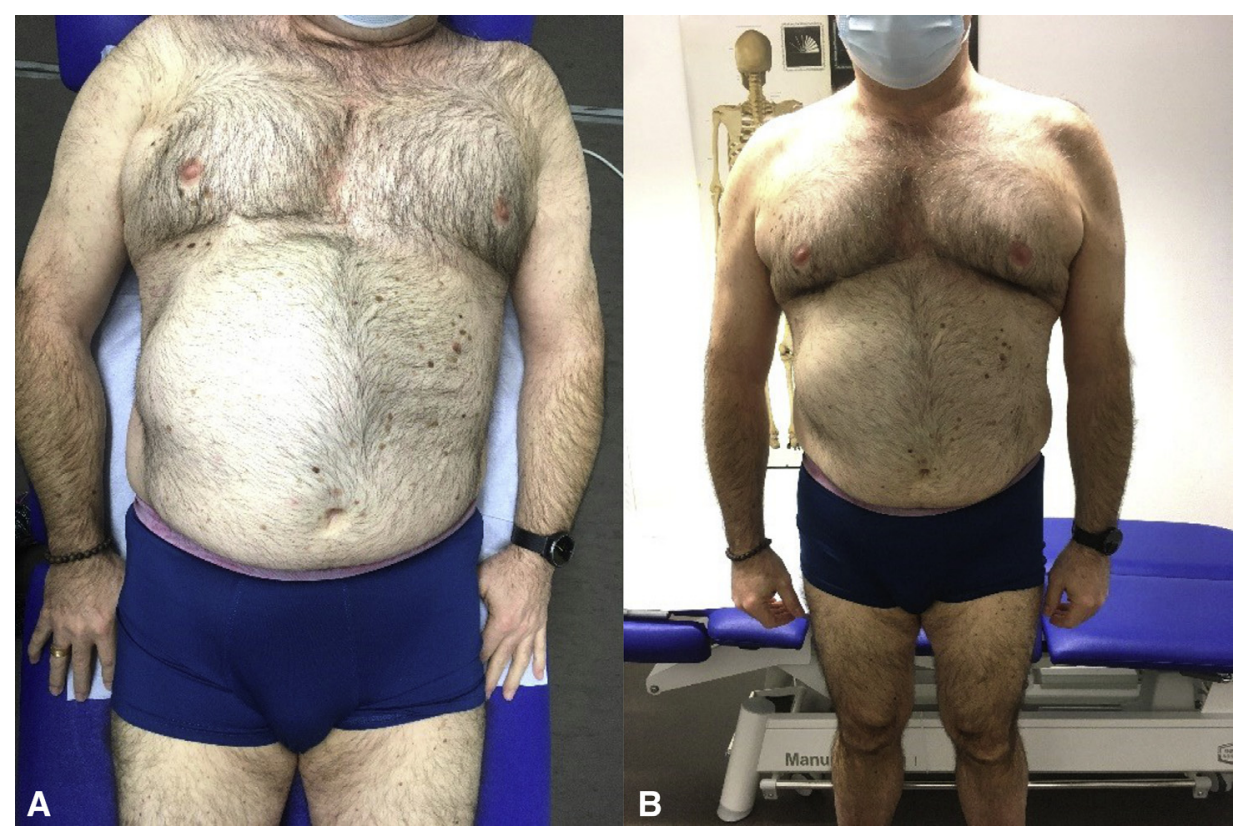

FIGURE 2. A, Patient 4 months after surgery. Abdominal swelling due to paralysis of the upper part of the rectus abdominal muscle and superior oblique at the level of dermatome Th6 through Th9. B, Patient 1 year after surgery. Persistent swelling is seen. Note: The reduced hair growth at the right abdominal side is due to shaving for physiotherapeutic reasons. 


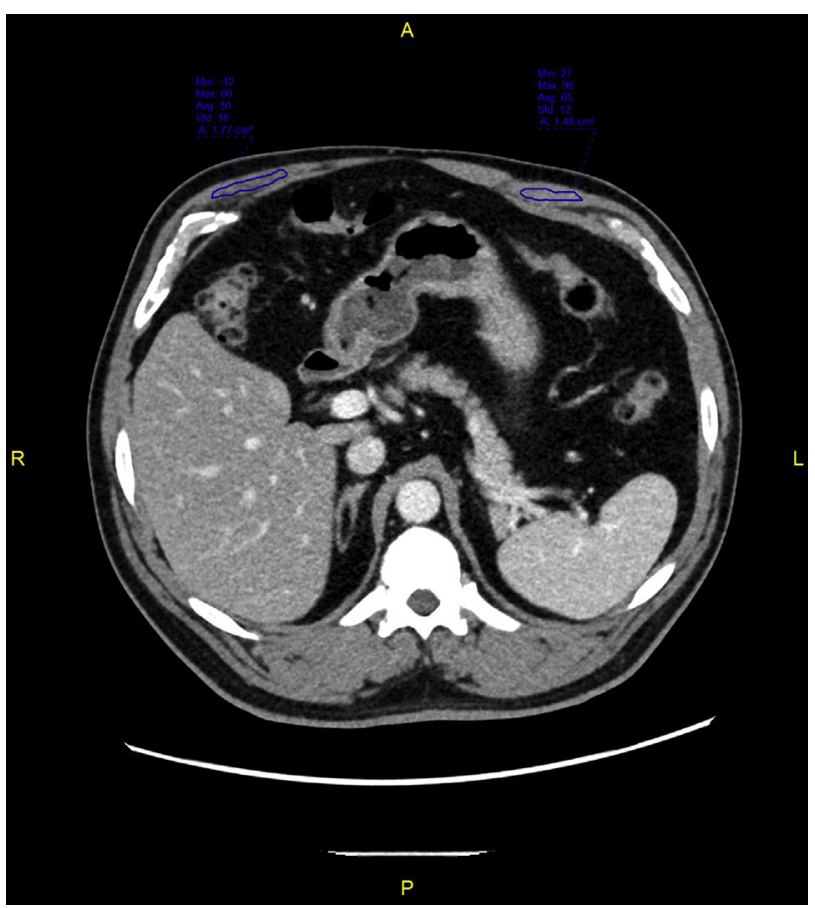

FIGURE 3. Computed tomography axial section of the lumbar spine at the level of Th12 for analysis of muscle density on the 2 sides. The atrophied right side of the rectus muscle became less dense as measurement in Hounsfield units (HU). A, Muscle thickness 0.52 versus $1.20 \mathrm{~cm}$. B, Density measurement 29 versus $66 \mathrm{HU}$. denervation of the upper two-thirds of the rectus and external oblique abdominal wall muscles. Retrospective image review confirmed rectus abdominis atrophy with lipomatous involution confirming concomitant muscle density loss (Figure 3).

\section{DISCUSSION}

The rectus abdominis muscle has many sources of blood supply, including branches of epigastric and intercostal arteries. The innervation is provided by continuations of lateral and anterior branches of Th7 through Th12 intercostal nerves.

Persistent pain after lung surgery can be severe and difficult to treat. However, prevention remains crucial and is incorporated in many multimodal pain protocols, including cryoanalgesia. Pathophysiological underlying mechanisms of postoperative pain are mainly attributed to direct intercostal nerve impairment induced by the surgery. ${ }^{4}$ Nerve injury can be explained by direct pressure on the nerve, as well as from stretch and consequent ischemia from perineural vessel injury or necrosis after hematoma. ${ }^{5}$ Paralysis of the rectus abdominis is an infrequent and even potentially underdiagnosed complication after lung surgery (Table 1). A possible explanation for postoperative nerve lesion can be the rigidity of the ports because they are not flexible at all. With the movement of the robotic arms, contusion can

TABLE 1. Literature overview

\begin{tabular}{|c|c|c|c|c|c|c|c|}
\hline $\begin{array}{l}\text { First author, } \\
\text { year, country }\end{array}$ & Journal & $\begin{array}{l}\text { No. } \\
\text { of case } \\
\text { reports }\end{array}$ & Type of surgery & $\begin{array}{l}\text { Site of port } \\
\text { placement or } \\
\text { incision }\end{array}$ & $\begin{array}{l}\text { Postoperative } \\
\text { symptoms }\end{array}$ & $\begin{array}{c}\text { Follow-up } \\
\text { time }\end{array}$ & $\begin{array}{c}\text { Presentation at } \\
\text { final visit }\end{array}$ \\
\hline $\begin{array}{l}\text { Timmermans } \\
2013 \text { the } \\
\text { Netherlands }\end{array}$ & Hernia & 3 & $\begin{array}{l}\text { 2x Thoracotomy } \\
\text { 1x Thoracotomy } \\
\text { converted } \\
\text { VATS }\end{array}$ & $\begin{array}{l}\text { 1/8th ICS } \\
\text { 2/port at 6th ICS, } \\
\text { incision at } 5 \text { th ICS } \\
\text { 3/incision just } \\
\text { above diaphragm }\end{array}$ & $\begin{array}{c}\text { 2x ABW asymmetry } \\
\text { 1x ABW asymmetry } \\
\text { + hypoesthesia }\end{array}$ & $\begin{array}{l}3 \mathrm{mo} \\
8 \mathrm{mo} \\
12 \mathrm{mo}\end{array}$ & $\begin{array}{l}\text { 1x complete resolution } \\
\text { 1x partial resolution } \\
\text { 1x persistent asymmetry }\end{array}$ \\
\hline $\begin{array}{l}\text { Patila } \\
2009 \\
\text { Finland }\end{array}$ & $\begin{array}{c}\text { Annals of } \\
\text { Thoracic } \\
\text { Surgery }\end{array}$ & 2 & $\begin{array}{l}\text { 1x VATS } \\
\text { 1x Thoracotomy } \\
\text { converted } \\
\text { VATS }\end{array}$ & - & $\begin{array}{l}\text { 1x ABW asymmetry } \\
\text { 1x ABW asymmetry } \\
\text { + pain }\end{array}$ & $12 \mathrm{mo}$ & $\begin{array}{l}\text { 1x complete resolution } \\
1 \mathrm{x} \text { persistent asymmetry }\end{array}$ \\
\hline $\begin{array}{l}\text { Lee } \\
2019 \\
\text { Korea }\end{array}$ & $\begin{array}{l}\text { Yeungnam } \\
\text { University } \\
\text { Journal of } \\
\text { Medicine }\end{array}$ & 1 & Thoracotomy & $\begin{array}{l}\text { Incision at 9th ICS, } \\
\text { chest tubes at 9th } \\
\text { and 10th ICS }\end{array}$ & ABW asymmetry & - & - \\
\hline $\begin{array}{l}\text { Antonescu } \\
2011 \\
\text { Canada }\end{array}$ & $\begin{array}{c}\text { Journal of } \\
\text { Pediatric } \\
\text { Surgery }\end{array}$ & 1 & VATS & $\begin{array}{c}\text { Ports at } 4 \text { th, } 7 \text { th } \\
\text { and } 5 \text { th ICS }\end{array}$ & $\begin{array}{l}\text { ABW asymmetry } \\
+ \text { sensory deficit }\end{array}$ & $2 \mathrm{mo}$ & $\begin{array}{l}\text { Persistent asymmetry, } \\
\text { resolved sensory } \\
\text { deficit }\end{array}$ \\
\hline $\begin{array}{l}\text { Cho } \\
2017 \\
\text { Korea }\end{array}$ & $\begin{array}{l}\text { Annals of } \\
\text { Thoracic and } \\
\text { Cardiovascular } \\
\text { Surgery }\end{array}$ & 1 & VATS & $\begin{array}{l}\text { Ports at } 5 \text { th, } 7 \text { th, } \\
\text { and } 8 \text { th ICS }\end{array}$ & $\begin{array}{l}\text { ABW asymmetry } \\
+ \text { hypoesthesia }\end{array}$ & $24 \mathrm{mo}$ & Persistent asymmetry \\
\hline
\end{tabular}

VATS, Video-assisted thoracoscopic surgery; $I C S$, intercostal space; $A B W$, abdominal wall; -, unknown. 


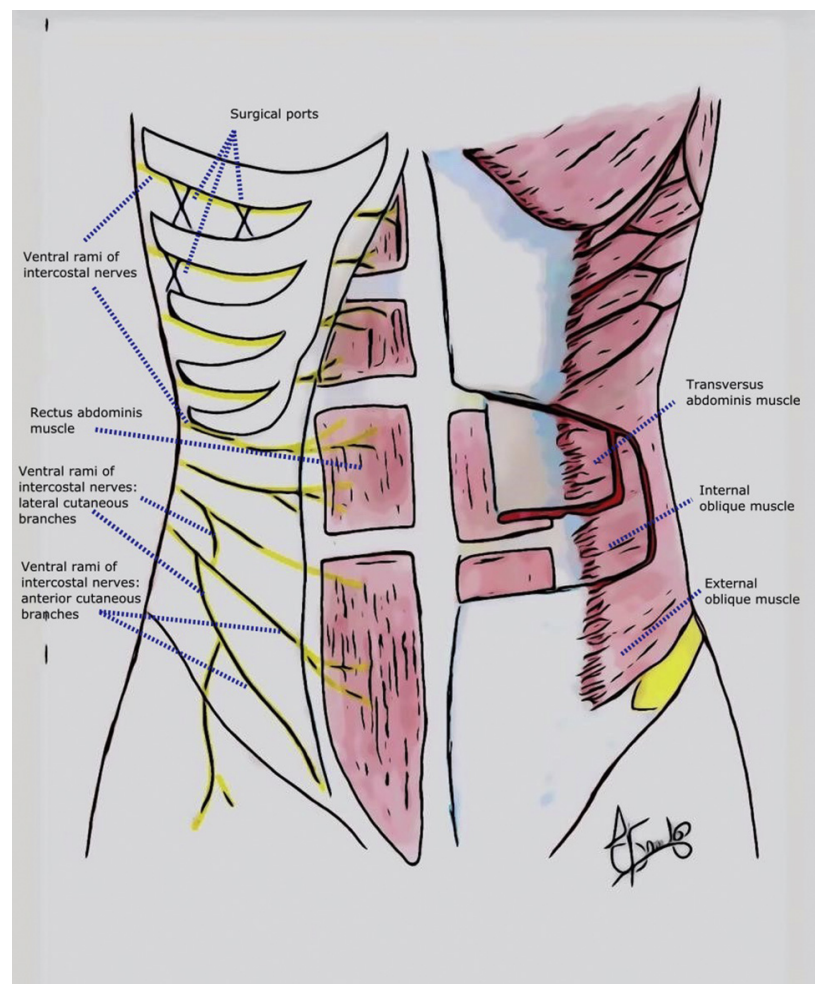

FIGURE 4. Overview of rectus abdominis muscle and nerve supply. The rectus abdominis muscle is a paired muscle running vertically on each side of the anterior abdominal wall, separated by the linea alba. It extends from pubis symphysis to the xiphoid process and costal cartilages of ribs 5 to 7 . The rectus has many sources of arterial blood supply, including branches of superior and inferior epigastric arteries, and numerous contributions from intercostal arteries. The innervation is provided by thoracoabdominal nerves (yellow), which are continuations of lateral and anterior branches of Th7 through Th12 intercostal nerves. Before entering the lateral side of the rectus sheath, this small nerve travels between the transverse abdominis muscle and the middle layer; that is, the internal oblique muscle. Robotic port sites are illustrated as black crosses. be caused at the level of the neurovascular bundle (Figure 4).

\section{CASE}

Muscle paralysis was the result of nerve compression (Seddon and Sunderland neurotmesis grade V) from the port site because the cryoanalgesia treatment was performed according to the gold standard technique. Moreover, this complication has been previously reported in the absence of any cryoanalgesia modality.

As expected, the hypoesthesia was reduced 10 months after surgery, which can be attributed to intercostal nerve regeneration. No hyperalgesia or allodynia was reported. Nevertheless, the prominent swelling exists more than 1 year postoperatively, with esthetic concerns (Figure 2, B).

\section{CONCLUSIONS}

Given the mix of sensory and motor function of intercostal nerves and the presence of chronic pain after lung surgery, muscle weakness as a postoperative lesion may be underreported. Although many techniques are designed for minimizing postoperative nerve injury, patients could be informed of the possibility of muscle asymmetry after thoracic surgical procedures.

\section{References}

1. Kehlet H, Jensen TS, Woolf CJ. Persistent postsurgical pain: risk factors and prevention. Lancet. 2006;367:1618-25.

2. Ilfeld BM, Preciado J, Trescot AM. Novel cryoneurolysis device for the treatment of sensory and motor peripheral nerves. Expert Rev Med Device. 2016; 13:713-25.

3. Jelinek LA, Scharbach S, Kashyap S, Ferguson T. Anatomy, Abdomen and Pelvis, An terolateral Abdominal Wall Fascia. Treasure Island, FL: StatPearls Publishing; 2017.

4. Miyazaki T, Sakai T, Tsuchiya T, Yamasaki N, Tagawa T, Mine M, et al. Assessment and follow-up of intercostal nerve damage after video-assisted thoracic surgery. Euro J Cardiothorac Surg. 2011;39:1033-9.

5. Menorca RM, Fussell TS, Elfar JC. Peripheral nerve trauma: mechanisms of injury and recovery. Hand Clin. 2013;29:317-30. 